\title{
APONTAMENTOS SOBRE RACISMO, PODER E ÉTICA
}

\author{
NOTES ON RACISM, POWER AND ETHICS
}

\author{
ERICK ASSUMPÇÃO \\ (Universidade Federal Fluminense, Brasil)
}

\begin{abstract}
RESUMO
Este artigo parte dos apontamentos de Judith Butler acerca de uma diferente alocação de vulnerabilidade entre os grupos humanos, tendo como fim a compreensão do funcionamento do racismo desde sua formulação no racismo de Estado até suas atuações noopoliticas. A partir daí, tem-se como proposta o debate acerca de uma ética possível para enfrentar o racismo.

Palavras-chave: Política. Vulnerabilidade. Biopoder. Noopolítica.
\end{abstract}

\begin{abstract}
This article has as point of departure Judith Butler's claim on the different manners of distribute vulnerability among human groups. We aim to comprehend racism's function from its configuration as racism of the State to its noopolitics acting. Through that, we have as proposal the debate on a possible ethics to confront racism.
\end{abstract}

Key words: Politcs. Vulnerability. Biopower. Noopolitics.

Este artigo tem como ponto de partida a afirmação de Judith Butler, presente no livro Precarious Life: the powers of mourning and violence, a saber: "[h]á formas de distribuir a vulnerabilidade, diferentes maneiras de alocá-la que fazem com que algumas populações sejam mais sujeitas à violência arbitrária do que outras” (BUTLER, 2004, p. XII). Ou seja, certas vidas têm ao seu redor aparatos de proteção, que por vezes, não apenas assemelham-se, mas são aparatos de guerra; enquanto, por outro lado, há vidas cuja vulnerabilidade é potencializada e danos são instalados.

Nesse sentido, podem ser feitas algumas convergências conceituais com o vocabulário específico da bioética: 1) a vulnerabilidade como "condição ontológica de qualquer ser vivo" (SCHRAMM, 2008, p.20); 2) a suscetibilidade como potencialização da vulnerabilidade, no sentido de maior propensão a danos e; 3) a vulneração como condição na qual algum dano já foi instalado e perdura-se a condição de suscetibilidade.

O que pode ser entendido como alocação de suscetibilidade e vulneração emerge como objeto deste trabalho. Em particular, Buscar-se-á trazer à luz um tipo específico dessa alocação: o racismo. A compreensão deste partirá do que Foucault denominou racismo de Estado, este uma reconfiguração do poder soberano.

Segundo Foucault, a atuação por meio do racismo assegura ao Estado uma função que 
remete à soberania, isto é, a "função assassina" (FOUCAULT, 2010, p. 215). Logo, tem-se como objetivo específico, apontar como se dá esse poder soberano - poder de fazer morrer por meio dessa vertente do racismo.

Ainda no campo dos estudos relativos ao poder, este trabalho tem como objetivo fazer apontamentos relativos ao racismo na atualidade, no sentido de compreender seu funcionamento.

Por fim, a guisa de conclusão, tratar-se-á, em diálogo com Agamben, da proposta de Judith Butler referente à possibilidade de uma ética sob a qual subjaz a vulnerabilidade como condição comum da humanidade, mas que não se abstém da compreensão acerca da distribuição geopolítica da vulnerabilidade (BUTLER, 2004), isto é, a existência da imposição de maiores graus de suscetibilidade individual e/ou coletiva respectiva a contextos históricos e sociais específicos.

\section{Distribuição da vulnerabilidade}

Judith Butler (2004) em Precarious Life: the powers of mourning and violence descreve a noção de vulnerabilidade atrelada à ideia da construção do sujeito. A autora aponta para o fato de que o sujeito não apenas se constitui por meio da relação eu-outro, mas é constantemente desfeito nesta relação. Neste sentido, torna-se possível pensar as maneiras pelas quais a dor e o luto desafiam a compreensão do "eu" como autônomo e no controle de suas próprias emoções. Esta vulnerabilidade que é compartilhada, no entanto, “[...] torna-se substancialmente exacerbada em certas condições sociais e políticas" (BUTLER, 2004, p. 29).

Delimita-se assim o que a autora compreende por uma distribuição geopolítica de vulnerabilidade, potencialmente desigual, onde alguns sujeitos e comunidades são mais suscetíveis, de acordo com condições sociais e políticas específicas, ao risco e à concretização de situações de vulneração. Assim, apesar de a vulnerabilidade e a exposição ao outro serem caracterizadas por Butler como condição comum

\footnotetext{
"[v]idas são apoiadas e mantidas diferentemente, há maneiras radicalmente diferentes segundo as quais a vulnerabilidade física humana é distribuída pelo globo. Certas vidas serão altamente protegidas e a revogação de suas reivindicações para a santidade será suficiente para mobilizar as forças da guerra. Outras vidas não encontrarão uma resposta de apoio tão veloz e furiosa e, mesmo, não serão qualificadas como vidas merecedoras de luto" (BUTLER, 2004, p.32).
}

Butler apresenta a questão: Que vidas contam como vidas? E ainda: Que mortes 
merecem ser veladas? A autora aponta, a partir do exemplo dos obituários, os processos de desumanização do Outro que são produzidos não somente através do discurso, mas através do silêncio e da omissão. No caso dos Estados Unidos, o obituário funciona como ato de construção da nação, definindo quais são os atores sociais reconhecíveis. Dessa forma, as crianças e adultos afegãos permanecem sem rosto, sem nomes, sem história: "[s]erá que nos sentimos compelidos a aprender a dizer esses nomes e lembrar-se deles?" (ID: 37). Por outro lado, as vítimas no World Trade Center que são exaustivamente mostradas e personalizadas, aparecem como figuras familiares cujas mortes são sentidas e veladas.

Dessa forma, a autora indica que há uma concepção restritiva do humano, baseada na exclusão de formas de vida específicas, que age no nível da ontologia, numa relação entre violência, vulnerabilidade e vidas que se tornam irreais. Como descreve Butler: "[a] irrealização [derealization] do Outro significa que este não está nem morto nem vivo, mas indeterminadamente espectral" (ID: 33-4).

Em suma, o Outro transita entre a condição de espectro, ignorado ou temido, e a de alvo ideal de técnicas e tecnologias de poder. Em específico, um poder de matar ou deixar viver característico da era absolutista: o poder soberano.

\section{Poder soberano e racismo de Estado}

A soberania pode ser compreendida por meio da equação "fazer morrer e deixar viver" segundo a qual o soberano atualiza seu poder por meio do direito de matar. "Na teoria clássica da soberania [...] o direito de vida e de morte [é] um dos seus atributos fundamentais" (FOUCAULT, 2010, p. 202). Direito característico das monarquias absolutistas que diferente de cessar juntamente com essas últimas se reconfigura e reorganiza. O que quer dizer que as formas de organização do poder (soberano, disciplinar, biopolítico e noopolítico) não se substituem nem de maneira linear nem arbitrária, mas, sim, integram-se e modificam-se. A soberania é uma forma de poder que se fundamenta em um ciclo sujeito-sujeito, ou seja, de um indivíduo sujeitado a outro. Um sujeito que é súdito, outro sujeito que é soberano.

"[E]m relação ao poder, o súdito não é, de pleno direito, nem vivo nem morto. Ele é, do ponto de vista da vida e da morte, neutro, e é simplesmente por causa do soberano que o súdito tem o direito de estar vivo ou tem direito, eventualmente, de estar morto. Em todo caso, a vida e a morte dos súditos só se tornam direitos pelo efeito da vontade soberana" (FOUCAULT, 2010, p. 202).

Na Europa, a partir do século XVII surge outra forma de organização do poder que se 
consolida no século XIX com um novo direito "que não vai apagar o primeiro [de fazer morrer e deixar viver], mas vai penetrá-lo, perpassá-lo, modificá-lo, e que vai ser um direito, ou melhor, um poder exatamente inverso: poder de 'fazer' viver e de 'deixar' morrer" (FOUCAULT, 2010, p. 202). O biopoder, como é denominado este "inverso" da soberania, constitui-se pela disciplina e pela biopolítica, e têm como objeto e objetivo a vida.

De forma mais específica, o poder disciplinar tem sua atuação pautada na manipulação do corpo individual. A partir da compreensão de que este corpo é dotado de forças, tal manipulação tem como objetivo torna-las, simultaneamente, forças dóceis e úteis. Tendo como referência este resultado ideal de docilidade e utilidade, a disciplina atua, em diferentes instituições, por meio de um modelo ótimo, uma norma, na qual se conformam corpos. Caso essa conformação não ocorra, são identificados os anormais. Existe na disciplina um processo que Foucault chama de normação $(2008$, p. 75).

Por sua vez, a biopolítica requer uma compreensão acerca do corpo segundo a qual este se encontra em um conjunto regido por processos biológicos. Logo, a biopolítica atuará nessa massa de corpos, ou como indica Foucault, nesta população, por meio do controle de possíveis eventos analisados através das taxas de natalidade, mortalidade, adoecimento, fluxos de circulação de pessoas e objetos, entre outras. Na biopolítica tem-se um processo de normalização (ID, p. 83). Busca-se, em primeiro lugar, a taxa normal de certo evento para, posteriormente, buscar intervir para adequar os eventos e suas interações a essa normalidade e seus efeitos mais favoráveis.

Estas técnicas e tecnologias regem uma rede de corpos e eventos relacionados a um processo de industrialização e de explosão demográfica. A função disciplinar das instituições - escolas, hospitais, quartéis, fábricas, prisões - e o papel regulamentador do Estado, asseguram o desenvolvimento, a manutenção e a defesa da sociedade na qual se localiza este processo.

Em princípio, o que é entendido como soberania seria inoperante neste contexto. Dessa forma, emerge a questão: como se exerce o poder soberano em paralelo ao biopoder, tendo em vista que seu efeito "sobre a vida só se exerce a partir do momento em que o soberano pode matar" (FOUCAULT, 2010, p. 202)?

Aqui intervém o racismo: a "função assassina do Estado só pode ser assegurada, desde que o Estado funcione no modo do biopoder, pelo racismo" (FOUCAULT, 2010, p. 215). Portanto, a manutenção do poder de matar em uma sociedade regida pela disciplina, regulação e controle dos corpos e da vida se dá por meio da fragmentação nesse contínuo biológico da 
espécie humana, fragmentação que é o racismo. "A raça, o racismo, é a condição de aceitabilidade de tirar a vida em uma sociedade de normalização" (FOUCAULT, 2010, p. 215).

Cabe, aqui, uma observação de Foucault sobre o poder de matar:

“[é] claro, por tirar a vida não entendo simplesmente o assassínio direto, mas também tudo que pode ser assassínio indireto: o fato de expor à morte, de multiplicar para alguns o risco de morte ou, pura e simplesmente, a morte política, a expulsão, a rejeição, etc.” (FOUCAULT, 2010, p. 216).

Logo, o poder soberano que atua em tempos de biopoder configura-se como um poder de morte direta ou indireta sob um grupo específico, diferenciado dos outros pela sua "raça". Cabe aqui uma síntese em quatro pontos feita por Lévi-Strauss da doutrina do racismo:

\footnotetext{
"Um: existe uma correlação entre o patrimônio genético de um lado, as aptidões intelectuais e as disposições morais de outro. Dois: esse patrimônio, de que essas aptidões e disposições dependem, é comum a todos os membros de alguns grupos humanos. Três: esses agrupamentos chamados 'raças' podem ser hierarquizados em função da qualidade de seu patrimônio genético. Quatro: as diferenças autorizam as 'raças' ditas superiores a comandar, a explorar as outras, eventualmente destruí-las" (LÉVISTRAUSS, 2005, p.212).
}

A síntese de Lévi-Strauss torna explícito o fato de que o racismo estabelece como determinante uma condição biológica da qual derivam conhecimentos e princípios específicos. Aqui, portanto, temos a vertente biológica, ou evolucionista, do racismo, como a apontada por Foucault. O termo raça, dessa forma, atua com vias a tornar legítimas as ações que tem como fim defender a sociedade, ou mais precisamente, membros de uma raça específica, e que tem como consequência a ampliação da vulnerabilidade em grupos específicos, configurando a condição de suscetibilidade; a implicação de danos e prejuízos materiais e imateriais, o que estabelece a condição de vulneração; ou a morte.

Em suma, o racismo "assegura a função de morte na economia do biopoder, segundo o princípio de que a morte dos outros é o fortalecimento biológico da própria pessoa na medida em que ela é membro de uma raça" (FOUCAULT, 2010, p. 217).

Ressalta-se, assim, o fato de que concomitantemente aos processos relativos ao funcionamento do biopoder na Europa associado à compreensão de cidadão, trabalhador livre, população, tem-se nas colônias o extermínio e o trabalho escravo, além de outras formas de trabalho compulsório, como base produtiva e social. Em princípio, subjacente a tais práticas se encontram doutrinas religiosas, sendo posteriormente substituídas, ou sendo adicionada a elas, a doutrina biológica. "O racismo vai se desenvolver primo com a colonização, ou seja, 
com o genocídio colonizador" (ID, p. 216).

Este "funcionamento" do racismo aponta para outra reconfiguração do poder soberano, aquela referente ao próprio soberano. O ciclo sujeito-sujeito característico da relação soberano-súdito se reconfigura e a soberania torna-se circulante, o que quer dizer que não se tem mais uma unidade de poder efetiva. Sendo assim, o poder de vida e de morte não é exclusivo do Estado, mas circula, com intensidades diferentes, por uma série de indivíduos, desde os senhores de engenho aos capitães do mato.

No entanto, como será apontado, entender-se-á a vertente evolucionista do racismo como insuficiente para o período atual. O que quer dizer que, por exemplo, não serão aprofundadas aqui as consequências dos estudos bioquímicos relativos à determinação de processos sociais a partir de características genéticas. Sendo assim, em que termos se pode pensar o racismo na atualidade?

\section{Racismo e articulações do poder}

É importante ressaltar o fato que o foco a ser tratado nesta etapa do artigo será o racismo relacionado à negritude. $\mathrm{O}$ ponto de partida será um discurso que exemplifica a insuficiência da análise do racismo atual por meio da vertente evolucionista, a saber: o discurso contra a política de cotas no Brasil, ou seja, a reserva de vagas para pessoas negras em universidades. Posteriormente, tratar-se-á dos aspectos noopolíticos do racismo relacionados a enunciações midiáticas. Finalmente, retornaremos para aspectos do racismo de Estado, por meio da análise do papel da polícia.

$\mathrm{O}$ argumento base do discurso contrário à política de cotas, assim como a outras políticas de ação afirmativa, é aquele segundo o qual privilegiar determinado grupo com uma porcentagem de vagas em concursos é errado, pois pessoas brancas e negras têm as mesmas possibilidades e capacidades, o que quer dizer que reservar vagas tem maiores consequências negativas do que positivas: a primeira seria uma racialização do país, ou seja, uma fragmentação em uma unidade diversa por meio da reinserção da atribuição de raça; a segunda seria o entendimento de que a política de cotas ao reinstaurar as raças parte do pressuposto de que as pessoas negras não são tão capazes como as brancas; a terceira derivase das anteriores, tendo em vista que a fragmentação e hierarquização postulada por este tipo de política levaria a uma ampliação do racismo.

De forma mais pontuada, o argumento segundo o qual a política de cotas geraria uma 
racialização de questões sociais, econômicas, políticas não leva em consideração o fato de que problemas socioeconômicos brasileiros, como a questão habitacional, foram fomentados por meio deste corte racial. O que quer dizer que o fato de que após as pessoas negras escravas serem libertas, no final do século XIX, as mesmas terem como destino trabalhos mal remunerados que concretizavam apenas a habitação em quilombos ou quartos alugados em cortiços e, além disso, a possibilidade, mesmo distante, de serem proprietárias de terras ou imóveis era impedida legalmente, - ou seja, todo o processo percorrido dos quilombos às favelas (CAMPOS, 2007) - não é levado em consideração.

O debate acerca das capacidades torna-se assim desprovido de sentido, pois o que se encontra em jogo não são questões relacionadas à ontologia das pessoas negras, mas sim aos fatos que atravessaram e atravessam a vida das pessoas que nascem com a pele escura e acabam por restringir materialmente e imaterialmente suas as possibilidades de escolha.

O que nos leva às considerações relativas à terceira consequência negativa postulada pelo discurso contrário à política de cotas, que pode ser exemplificado pelo artigo de Fry e Maggie (2004). Este discurso torna explícito o caso da postulação de uma igualdade, proveniente da diversidade da mestiçagem, que acaba por ignorar, ou mascarar, aspectos históricos e sociais específicos que tornam certo grupo mais suscetível. Dessa forma, o discurso de igualdade acaba por manter, por um lado, a condição privilegiada de um grupo, nesse caso as pessoas brancas, e, por outro, a condição de suscetibilidade das pessoas negras. Ou seja, o discurso da igualdade apropria-se da negação da ideia de raças para manter o privilégio conquistado historicamente por meio do racismo em suas vertentes religiosas e, como tratado aqui, biológica. Portanto, há um deslocamento da vertente biológica do racismo para uma vertente que pode ser chamada de a-histórica.

Destaca-se que tais discursos não estão restritos ao campo acadêmico, mas circulam por uma rede midiática extensa que engloba sistemas monopolizados de informação, como a televisão, até meios mais abertos de troca, como a internet. Estes discursos atuam menos em um sentido de mera divulgação dos fatos, por meio de notícias, ou de entretenimento do que de estratégias em um campo de "relações de poder [que] se expressam pela ação a distância de uma mente sobre outra, pela capacidade de afetar e ser afetado dos cérebros" (LAZZARATO, 2006, p. 76). Estas relações configuram o que se chama noopolítica.

Estes dispositivos midiáticos buscam uma intervenção específica na mente, isto é, buscam intervir na capacidade de relacionar passado, presente e futuro da qual se criam sensações, fluxos de desejos e de crenças, sendo que a partir deste processo torna-se possível construir-se e atualizar-se como indivíduo. 
Em conjunto com as produções materiais do racismo visíveis, por exemplo, na organização da cidade, tem-se uma produção imaterial cuja atuação se perpetua ao cercear a capacidade de construção e atualização de indivíduos e grupos atingidos pelo racismo em quatro sentidos: 1) busca pelo impedimento da possibilidade deste sujeito entender-se como "objeto" de práticas racistas (busca mais severa do que aquela referente ao impedimento do sujeito de se entender como integrante do que poderia ser chamado de raça); 2) caso o sujeito chegue ao ponto deste entendimento, busca-se a limitação deste ao ponto de conhecedor passivo da condição de "objeto" do racismo. Ou seja, as ações de denúncia das produções do racismo estão além deste sujeito; 3) caso o sujeito atinja o ponto de denúncia, procura-se desqualifica-la, por vezes utilizando-se da inversão "as pessoas negras são as mais racistas" ou "o racismo está na mente de quem o vê". O livro Yearning: race, gender and cultural politics no qual bell hooks (1990) explicita o estreitamento do espaço de crítica desde pessoas negras relativa às representações na mídia do que poderia ser entendido como cultura negra torna explícito este terceiro ponto; 4) a partir do momento que o sujeito além do ponto de crítica, alcance o ponto de criação, isto é, ao ponto de fomento de outras possibilidades para além das atuais, uma das ações é a criminalização. Esta transcorre do imaterial ao material. Em outras palavras, parte da noção de criminalização subjetiva ("isto que faço é errado") à criminalização policial. A criminalização é um ponto articulador entre as técnicas e tecnologias de poder.

O fomento de outras possibilidades a partir da criação pode ser exemplificado pelas favelas e ocupações urbanas majoritariamente habitadas por pessoas negras. De maneira breve pode-se compreender estas formas de habitação como uma possibilidade inédita de manter-se próximo aos polos de trabalho, de equipamentos urbanos e de entretenimento a partir de uma criação coletiva empreendida pelos grupos atingidos negativamente pelos problemas relativos à habitação. A partir desta criação emerge a produção e a veiculação "de um determinado sujeito a ser combatido: o invasor" (ASSUMPÇÃO, 2012, p 136).

A produção deste sujeito atua em três direções: uma relativa aos sujeitos agentes das favelas e ocupações, ou seja, no sentido da produção do "isto que faço é errado: sou um invasor/sou uma invasora". Um relativo ao restante dos habitantes da cidade na direção do entendimento de que as pessoas faveladas e ocupantes não são parte da cidade, são espectros a serem ignorados ou temidos. Um relativo à defesa desta cidade legítima por meio da polícia.

Este caráter espectral ou fantasmagórico está presente no filme "O Som ao Redor" do diretor Kleber Mendonça Filho. O filme se passa em uma rua de classe média da zona sul de 
Recife cujos habitantes, majoritariamente brancos, aparecem em situações cotidianas características dessa classe, como reuniões de condomínio, irritação com o latido do cachorro do vizinho, aulas de inglês e mandarim, tendo como uma mudança de rumo nesse dia-a-dia o aparecimento de um grupo de seguranças particulares oferecendo seus serviços. No entanto, os aspectos do filme importantes aqui são o pesadelo da menina branca no qual sua casa é invadida por uma multidão de pessoas negras e a aparição fantasmagórica de um menino negro sem camisa que perambula pelos telhados, pelas casas e pelas copas das árvores. Esse último "fantasma" tem sua derradeira aparição quando é reprimido e atacado pelos seguranças da rua, ou seja, ele passa de uma ameaça fantasmagórica às pessoas brancas de classe média a alvo real da violência daqueles que servem a esta classe.

A condição de espectros ignorados ou temidos possibilita a ação do que Agamben (2002) chama de polícia soberana, tendo em vista que esta adquire o papel de decidir sobre cada situação para além de uma função de mera execução do direito. Dessa maneira, a atuação da polícia soberana sustenta-se "[n]a criminalização do adversário" (AGAMBEN, 2002, p. 118). O Outro se torna adversário e inimigo e, consequentemente, "o inimigo é desde o início excluído da humanidade civil e declarado criminoso" (AGAMBEN, 2002, p. 119). O Outro da cidade, o Outro do branco, tornam-se inimigos e criminosos a serem combatidos. Logo, a soberania policial atua sobre corpos negros, favelados ou ocupantes, tendo como base o processo de produção subjetiva do invasor, sujeito posicionado em oposição ao interesse e ao desenvolvimento da cidade, sendo assim, as favelas e ocupações são alvos de medidas como remoções, despejos e militarização (um exemplo são as Unidades de Polícia Pacificadora UPP).

Este último caso apresenta-se como exemplo paradigmático, pois é um ponto articulador entre as técnicas e tecnologias de poder, tendo em vista que se configura como

\footnotetext{
"poder soberano que pode decidir entre matar e deixar viver, poder disciplinar de vigilância dos corpos e como poder noopolitico, a partir do momento que enuncia a si própria como polícia comunitária, como vizinha, como "o mesmo" que as pessoas moradoras das favelas. Dessa forma, chegase a instaurar uma polícia mediadora de pequenos conflitos, uma polícia que espera e transforma cada indivíduo em possível bandido ou 'X9'" (ASSUMPÇÃO, 2013, p. 149).
}

Em suma, o racismo na atualidade é um ponto de fluxos no qual transpassam técnicas e tecnologias de poder em suas diversas formas desde as relativas ao poder soberano reconfigurado em racismo de Estado até as relacionadas à noopolítica. Pode-se então retomar o que Butler chama de distribuição geopolítica da vulnerabilidade, o que quer dizer que os 
espaços e corpos majoritariamente de pessoas negras são alvos de estratégias de poder em seus diferentes aspectos e possuem como produção a ampliação da condição de vulnerabilidade, acarretando a suscetibilidade e concretizando a vulneração.

\section{Conclusão para uma ética possível}

Parte-se do fundamento de uma ética possível proposta por Agamben segundo a qual o:

\footnotetext{
"fato de onde deve partir todo o discurso sobre a ética é o de que o homem não é nem terá de ser ou de realizar nenhuma essência, nenhuma vocação histórica ou espiritual, nenhum destino biológico. É a única razão por que algo como uma ética pode existir: pois é evidente que se o homem fosse ou tivesse de ser esta ou aquela substância, este ou aquele destino, não existiria nenhuma experiência ética possível - haveria apenas deveres a realizar" (AGAMBEN, 1993, p. 38).
}

Este fundamento pode ser posicionado, de forma contundente, em oposição às vertentes religiosa e biológica de racismo. Assim como em oposição àquela vertente $a$ histórica do racismo, tendo em vista que ao se apropriar da negação da ideia de raças, essa vertente nega também os aspectos históricos derivados das vertentes de racismo anteriores que atravessam os indivíduos e grupos negros delimitando material e imaterialmente suas vidas. Logo, esta vertente faz emergir a compreensão de que a condição atual da negritude concretiza-se por meio de algum tipo de infelicidade do destino, já que as oportunidades estão presentes para todas as pessoas.

Tem-se uma base, então, na compreensão da inexistência de qualquer teleologia, qualquer fim a chegar, substância ou natureza a realizar. Como afirma Kabengele Munanga (2003), nenhum indivíduo pode ser reduzido a algo que supostamente o define ou possa defini-lo. Nesse sentido, Butler, a partir dos apontamentos sobre a política interna e externa dos Estados Unidos pós-11 de setembro, propõe uma ética que leve em consideração um aspecto comum que não reduz indivíduos ou grupos a certa definição, mas uma condição compartilhada pela humanidade, a saber: a vulnerabilidade da vida humana e a facilidade com que esta pode ser anulada. A autora propõe levar em conta os efeitos transformadores da perda, retirando a dor de seu sentido puramente localizado no privado, no indivíduo, para pensar um senso de comunidade política que emerge do luto.

Entende-se a proposta de Butler no sentido de que a vulnerabilidade, aquilo que 
usualmente fragmenta os grupos humanos por meio do receio de ataque e propicia o estabelecimento de aparatos de defesa, pode se tornar o que consolida uma comunidade, desde que, contextualizando os escritos de Butler ao contexto deste trabalho, aquela vida negra na favela não seja atingida negativamente de forma arbitrária e, caso isso venha acontecer, esta perda não seja menos valorizada/velada do que aquela atingida no asfalto "legítimo" da cidade.

Sendo assim, a proposta de Butler pode ser estabelecida se forem deixados de lados os argumentos racistas de defesa da sociedade, como aquele acerca da produção e do ataque ao invasor seja ele a pessoa favelada ou ocupante. Ou seja, é necessário deixar as vocações compreendidas como universais, como aquelas relativas a uma cidade ideal. Portanto, ética não é uma vida que segue universais:

“[é]tica não é a vida que simplesmente se submete à lei moral, mas a que aceita, irrevogavelmente e sem reservas, pôr-se em jogo nos seus gestos. Mesmo correndo o risco de que, dessa maneira, venham a ser decididas, de uma vez por todas, a sua felicidade e a sua infelicidade" (AGAMBEN, 2007, p. 61).

Pensar em ética em tempos de racismo articulado em diferentes técnicas e tecnologias de poder significa pensar nos grupos privilegiados colocando-se em jogo com as outras vidas suscetíveis e vulneradas, tanto no sentido de abaixar seus aparatos de defesa-ataque quanto naquele de mitigar os efeitos do racismo nestes grupos por meio de ações afirmativas. Mas, sobretudo, significa pensar e apoiar a produção de outras formas de vida desde os grupos suscetíveis e vulnerados, produções como as favelas e as ocupações urbanas. 


\section{Referências bibliográficas:}

AGAMBEN, G. A comunidade que vem. Lisboa: Presença, 1993.

. Moyens sans fins. Notes sur la politique. Paris: Payot \& Rivages, 2002.

Profanações. São Paulo: Boitempo, 2007.

ASSUMPÇÃO, EA. Uma batalha urbana: poder e resistência na cidade do Rio de Janeiro.

Rev. Inquietude, 2012, v.03, $\mathrm{n}^{\circ}$ 02. Disponível em:

http://www.inquietude.org/index.php/revista/article/view/200/193.

ASSUMPÇÃO, EA; FRANCO, TB. Por uma cidade menor: hegemonia e resistência na cidade do Rio de Janeiro. Rev. Lugar Comum, 2013, nº 39, pp. 144-155.

BUTLER, J. Precarious Life: the powers of mourning and violence. London/NY: Verso, 2004.

CAMPOS, A. Do quilombo à favela: a produção do "espaço criminalizado" no Rio de Janeiro. Rio de Janeiro: Bertrand Brasil; 2007.

FOUCAULT, M. Em defesa da sociedade. 2ª edição. São Paulo: Martins Fontes; 2010.

. Segurança, Território, População. São Paulo: Martins Fontes; 2008.

FRY, P; MAGGIE, Y. "Cotas raciais: construindo um país dividido?" Econômica, 2004, vol. 6, n' 1 , pp. 153-161.

Hooks, b. Yearning: race, gender and cultural politics. Boston: South End Press; 1990.

LAZZARATO, M. As revoluções do capitalismo. Rio de Janeiro: Civilização Brasileira; 2006.

MUNANGA, K. Diversidade, etnicidade, identidade e cidadania. Ação Educativa, ANPED. Palestra proferida no $1^{\circ}$ Seminário de Formação Teórico Metodológica-SP. 2003.

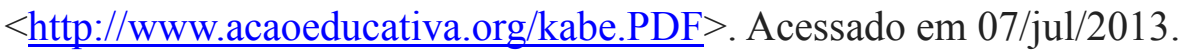

LÉVI-STRAUSS, C. De perto e de longe. São Paulo: Cosac \& Naify, 2005.

SCHRAMM, FR. Bioética da proteção: ferramenta válida para enfrentar problemas morais na era da globalização. Rev. Bioét. (Impr.) 2008; 16(1):11-23 